\title{
Forming of Innovative Development Mechanism of the Ukrainian Economy in the Context of Ideas of V.I.Vernadskiy
}

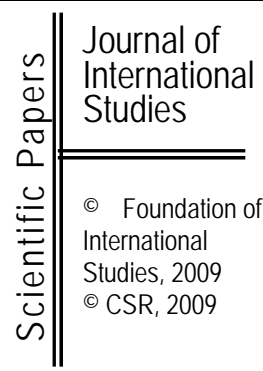

\author{
Dr. Yuriy Yamko \\ Director of department of the structural analysis \\ Vernadsky Natural Economic Institute, Kyiv \\ yuriyyy@,rambler.mu
}

\begin{abstract}
The necessity of trajectory transformation of economic development of Ukraine in the direction of providing of sustainable development on regional, industrial and individual levels does not cause doubts. However such indissolubly connected spheres as economy, society and natural environment were examined by science as isolated, as a result humanity ran into challenges of post-global character. The attempts of modern science to decide single tasks at high professional level do not result in the decision of general tasks of providing of sustainable development, as the world entered into the age of challenges of former paradigm of world development. It is necessary to see integrity and in the decision of the applied tasks to pass from whole to the details. The age of not so much analysis and private knowledge, but synthesis and synergetic of knowledge, came. In this context studies of V.I Vernadskiy about neosphere today as never are claimed, because it gives the integral picture of natural cycles of migration of matter and energy and role and place of man in the process of change of biosphere of Earth, transformation of man.
\end{abstract}

Keywords: innovative development, sustainable development, challenges of globalization, system crisis, system of values.

Submitted: February, 2009

1st revision: April, 2009

Accepted: May, 2009

JEL classification: Q32, Q56, P2.

\section{Introduction}

The key task of forming an innovative model is providing of structural changes in an economy in the direction of growth of role of highly technological industries with the large part of the added cost, high technological mode.

To beginning of 2009 the cross flow of capitals is practically halted in a world scale, the recession of leading economies of the world grows.

Attempts of the use of traditional methods of revival of economies through financing of producers of commodities and services straightly, stimulation of consumption and consumers, and inflowing in the bank sector do not give the expected results. We have a situation, when we react on a danger only then, when it showed up already. A timely awareness also can appear unavailing, if influence on a situation is above our possibilities.

Development in a center of which is only production is already doubted, it forms the necessity of change of paradigm - from ideology of accumulation of financial riches to 
ideology of reasonable sufficientness, from ideology of competition to ideology of mutual help.

The purpose of this article is determination of main challenges for Ukraine and basic philosophical conception of providing of sustainable development.

\section{The present state}

The essence of civilization collision of globalization and development in the doctrine of neoliberal economic and social philosophy, formed neoliberal thought as an instrument of destruction of structures of people life-organization, their cultures, insensitive to those risks and dangers which hide in itself exempt market forces at modern technology, the substitution of the fundamental system of priorities of human life values by the category of «money».

Civilization reality is the opposition of the not so much states, but informativeideological platforms, having in the base the different systems of the value co-ordinates. This opposition is only intensified on a background of scarcity of accessible planetary resources, and this fact is simply impossible not to notice.

A public requirement must become the basis of new world view in social justice. The construction of bases of social justice requires the revision of principles of construction of mutual relations of objects and management subjects, criteria of determination of optimum sufficientness, that gives us nature and human activity with the purpose of reproduction of lost, maintenance of present natural resources, human, including intellectual potential, for their application and comprehensive development in the future.

The socio-economic system appeared before of long duration system challenges, reflecting world tendencies.

The first challenge is strengthening of global competition, wrap-round not only the traditional markets of commodities, capitals, technologies and labor force, but also systems of national management, support of innovations, development of human potential.

The second challenge is the expected new wave of technological changes, sharply strengthening role of innovations in socio-economic development and depreciating many traditional factors of growth.

development.

The third challenge is growth of role of human capital as a basic factor of economic

\section{Diagnosis of the problems}

The first comprehensive analysis of development of technical civilization was executed by the members of the Roman club, authorities in the different areas of science, technique and economy. In the final labor of «Limit of growth» in 1972 they presented the results of design of tendencies, related to the uncontrolled use of Earth resources.

Basic conclusions consisted in that at the rates of development, which exist at that time, unrenewable resources will end, the irreversible processes of disintegration of the world economic system will come whereupon, and that attempts of any particular solutions of problem cannot be successful.

The second reason of destruction of the system can be violation in ecosystem of Earth. Result will be the same, regardless of what terms will be executed before: exhaustion of resources or elimination of place of existence.

For 30 years the prognoses of the Roman club were not refuted, except for one: authors of research made a mistake in the estimation of rates of expense of resources process goes faster. The speech goes about survival in the conditions of the planetary limited resources. 
A system crisis cannot be solved by private, separate actions which will be characteristic at making a decision in motion. Such efforts can be effective and relatively successful, if they will have a well carefully created plan, realized and perceived by people.

The cross flow of capitals is practically shut-down in a world scale, that is related mainly to the search of the value equivalents, by determination of usefulness of one or another product for a man in the future.

The uncertainty and irrationality in determination of usefulness of product decisions of company from the side of user, that is full enough considered by the authors of theory of usefulness (Bernullian expected usefulness (Bernoulli), the expected usefulness vonNeumann-Morgenstern (Neumann and Morgenstern), theory of reliable equivalents (Schneeweiss, Handa, Finetti), subjective expected usefulness (Edwards, Rasey, Savage, Quiggin), theory of prospects (Kahneman and Tversky), subjective self-weighted usefulness (Karmarkar). Appears, that the state of affairs is conditioned by the authors who examined important, but private questions in tearing away from the general paradigm of civilization development.

As world experience, summarized on world summits on sustainable development in Rio-de-Janeiro (1992) and Johannesburg (2002), rotined, the limit of economic development of territory is an ecological limit, i.e. ability of the natural systems to overcome the consequences of activity of man. Today sustainable development must be understood foremost as the ecologically balanced, sustainable development, allowing saving the resource reproduction functions of environment (biosphere, hydrosphere, atmosphere, lithosphere), providing the protracted development of life and human civilization on our planet.

Principle approaches of the development of conception of the program of biocompatible sustainable development of the regional socio-economic system answer the modern view of directions of development of humanity, the main idea of EXPO-2005 Wisdom of nature. Wisdom of nature is understood as human wisdom, aspiring to realize civilization in harmony with nature, and the sources of this wisdom are innovative approaches and their successful use. Today the main task of the modern countries is making of the new decisions of global problems, on condition of maintenance of various individual features and consuetude's of world cultures and civilizations.

In accordance with the declared motto of EXPO-2005 Wisdom of Nature is exposed as:

- Matrix of Nature is understanding of mechanisms of nature - difficult interrelation between life, information and universe.

- An art of life is understanding of mechanisms of nature, found in world cultures, art, social norms and technological ethics in the past and present which opens possibilities for the future.

- Development of ecosocieties is creation of new way of life, in which a company and government plan and develop a production, consumption, development and conservancy for support of exactly that way of life, which provides harmony of human and nature.

\section{Remedies}

Progressive international public and world non-state analytical centers offered the new approach of overcoming of the noted negative moments - Conception of sustainable development of humanity.

The scientific base of Conception of sustainable development of humanity is Conception of Neosphere which was offered by an academician V.I. Vernadskiy in the beginning of XXI century and essence of which consists in obligatory co-ordination of 
ecological, economic and human development so that from a generation quality and safety of life of people did not diminish to the generation, the state of environment was not worsened and there was social progress.

Embodiment of Conception of sustainable development of humanity is oriented to the account in a state case frame as unique whole ecological, social and economic spheres without the return of advantage outwardly to attractive development only of economy in the conditions of market.

Spatial sustainable development of region is based on its determination as economic space, which engulfs the dynamic processes of territorial recreation and territorial productiontechnological cycles on the issue of products and grant of services which take a place within the limits of the given territory.

The estimation of complexity of regional development in an integrated kind in the quantitative and high-quality measuring an ecological, economic and social constituent at national level is provided the use of Index of sustainable development. At regional level are used Indexes of regional socio-economic development and of regional human development which provides a complete account only by an economic and social constituent and the account of ecological constituent is mediated.

Scientific meaningfulness of studies of Vernadskiy about neosphere is in that he as a naturalist, probing the geochemical processes of migration of matter and energy in nature, exposed the geological role of life, living matter in planetary processes, in becoming and subsequent maintenance of dynamic equilibrium of biosphere - product of life functions and environment of existence of living creatures. In this living matter he selected a man as geological force, changing the natural biogeochemical processes of planet, able to reconstruct in obedience to the presentations the natural cycles of migration of matter and energy folded during many geological epochs and to change the biosphere of Earth.

A task of creation of neospere is a task of today. Its decision is related to combining of efforts all of humanity, with claim of new values of collaboration and intercommunication of all of people of the world.

Neosphere is the state of natural environment consciously created a man. It is plugged in permanent development of natural processes of nature, but it is the natural environment of his existence controlled by man. As such state is not yet attained, so it is prematurely to name the modern stage of change of biosphere - the neosphere, and, that Vernadskiy understood under such, is the «intellectual sphere», intensifying of ecological situation abroad activated interest to the problem of co-operation of nature and society, anthropogenic influence on the biosphere of Earth.

A conference in Rio de Janeiro of 1992 gave appearance of term of sustainable development and attempts of creating of program of sustainable development. But was not said the most important: that it is necessary to learn to save not only separate biological kinds but also the whole ecosystem, that it is necessary to produce bases of demographic policy and that it is necessary, finally, to make the main purpose of all scientific activity the problem of providing of koevolution of nature and society, to begin the development of the new structure of public relations in a single planetary association and change the structure of public values.

\section{Recapitulation}

The ideas of neosphere are extraordinary at the same time. It, undoubtedly, is determining in forming of conceptions of koevolution of nature and society and ecological production.

Essentially, theory of neospheregenesis new principles of morality, new system of dispositions, which must be universal for all of planet, are underlaid, at all of distinction of 
civilizations of inhabiting it people. When at the beginning of XX age Vernadskiy said that once a man will have to undertake responsibility for development of both nature and society, he thought scarcely, that this time would come so soon. In the conditions of already coming ecological crisis inability of modern planetary association becomes clear with him to manage. The structure of public organization must suffer cardinal changes.

Development of basic economic infrastructure must be examined as destructive not interference with a biosphere, but as the improvement of quality of biosphere needed as such, and also as such form of improvement which approaches a biosphere to the higher level, doing it part of neosphere.

It is contingent by the structure of human production activity which includes:

At first, recreation of man as socially physiology individual. It includes the own recreation (birth) of man, as a biological person, renewal and development of his physical and spiritual forces, education, studies, self-education and bringing in to the culture, satisfaction of domestic necessities and intercourse on interests.

Secondly, recreation of financial resources of existence of man as process of mastering of objective reality for the power filling of life functions, in other words it is a process of active transformation of nature by people with the purpose of creation of necessary financial terms for the existence, which provides filling of matter and power human life functions in a specifically incident to him form, by creation of the objects of consumption and productiontechnical complex, mediated mastering of natural substrata of a man.

Thirdly, a recreation of spiritual cultural values as a process of forming of public consciousness as a result of the imaginary and physical mastering of the world, so the creation, distribution and consumption of spiritual values which determine a public world view - system of the generalized looks to the objective world and place of man in it, on attitude of people toward reality, to society and themselves, and also conditioned by these looks of their persuasion, ideals, principles of cognition and activity.

The construction of the social-economic system on the basis of ideas of neosphere of V.I. Vernadskiy is necessary to examine as the basis for forming of mechanism of innovative development of the Ukrainian economy.

\section{REFERENCES:}

1. Bilorus O.G. The global prospect and sustainable development: (System marketing researches) / O.G. Bilorus, U.M. Maceyko. - K.: IAMP, 2005. - 492 p. - Bibliogr.: p. 474-491;

2. Zang V.B. «Synergetics economy. Time and changes in a nonlinear economic theory». - M. «World», 1999. - 335 p.;

3. Vernadskiy V.I. Biosphere and neosphere. - M.: Ayris-press, 2004.;

4. Porter M.E. International competition. - M.: International relations, 1993.- 896 p. 